\section{Estudo de alcalóides de Pilocarpus pennatifolius Lemaire}

\section{E. M. R. de A. Lucio; N. Sharapin ${ }^{2 *}$; H. S. França ${ }^{3}$}

${ }^{1}$ Departamento de Química Geral e Inorgânica, Instituto de Química, Universidade Federal Fluminense

${ }^{2}$ Laboratório de Tecnologia de Produtos Naturais, Faculdade de Farmácia, Universidade Federal Fluminense, R. Mário Viana, 523, Bairro Santa Rosa, 24241-020, Niterói, RJ, Brasil

${ }^{3}$ Graduação (Curso de Farmácia)

elisabethmlucio@bol.com.br

sharapin@uol.com.br

\section{Resumo}

O gênero Pilocarpus da Família das Rutáceas compreende 13 espécies neotropicais espalhadas na região situada entre os trópicos de câncer e capricórnio. No Brasil são encontradas 9 espécies, que recebem designação geral de jaborandi ${ }^{1}$, fonte industrial de pilocarpina, utilizada no tratamento de glaucoma. A pilocarpina é produzida no país, em escala industrial, a partir do P. microphyllus Stapf, nativa do Estado do Maranhão. Umas das espécies botanicamente próxima a $P$. microphyllus é a P. pennatifolius Lem. O método empregado de análise foi segundo a Farmacopéia Suissa IV Ed. (modificado), que avalia o teor de alcalóides totais, expressando o resultado em pilocarpina. A evidenciação dos alcalóides secundários se deu através de cromatografia de camada fina (CCF). A análise dos resultados obtidos indicam que dificilmente a espécie constituirá um substituto para matéria-prima de extração de pilocarpina, visto que o teor da mesma em $P$. microphyllus chega a ultrapassar $1,0 \%$. A presença de diversas manchas na $\mathrm{CCF}$ recomenda o isolamento e identificação dos alcalóides secundários para a complementação da informação bibliográfica.

O gênero Pilocarpus, da família das Rutáceas, abriga diversas espécies que recebem designação geral de jaborandi ${ }^{1}$. Embora várias espécies tivessem sido utilizadas outrora para fins terapêuticos (como sudorífero), hoje em dia a espécie $P$. microphyllus Stapf. é a única fonte industrial de pilocarpina, alcalóide utilizado no tratamento de glaucoma ${ }^{8,9,11}$. É utilizada, também, para relaxamento intestinal após laparotomia e em xerostomia pós-radiação em pacientes com câncer de cabeça e pescoço.

Toda a matéria-prima para a extração de pilocarpina provém de plantas nativas. O estado do Maranhão é o principal produtor de folhas de jaborandi no Brasil, produzindo aproximadamente $95 \%$ da produção nacional ${ }^{7}$. A descaracterização do habitat do jaborandi e a exploração predatória, aliada à coleta de folhas de plantas muito jovens, particularmente na última década, resultaram na queda de produtividade e do teor médio de pilocarpina?

A escassez das folhas de P. microphyllus e a queda do teor médio de pilocarpina tornam necessária a procura de espécies relacionadas, que possam substituir o P. microphyllus como matéria-prima na obtenção da pilocarpina.

Uma das espécies botanicamente próxima a $P$. microphyllus é a $P$. pennatifoluis Lem. As suas folhas contêm pilocarpina e alcalóides secundários, entre os quais a isopilocarpina, esta inativa farmacologicamente ${ }^{2}$. Esta espécie nunca foi investigada quanto ao teor de pilocarpina e os seus alcalóides secundários (exceto a isopilocarpina) nunca foram identificados. A área de ocorrência de $P$. pennatifolius compreende os estados de Goiás, Mato Grosso, Paraná, Santa Catarina e Rio Grande do $\mathrm{Sul}^{7}$. A determinação dos teores de pilocarpina e da natureza dos alcalóides secundários poderá converter esta espécie em substituto da espécie $P$. microphyllus na exploração industrial. Considerando a demanda reprimida de pilocarpina no mercado mundial, o aproveitamento de $P$. pennatifolius poderá resultar no incremento das importações da pilocarpina e consequente aumento da entrada de divisas no País.

Os resultados obtidos mostram um teor médio de alcalóides totais variando de 0,4 a $0,5 \%$ calculados sobre o peso de folhas secas. O teor de pilocarpina varia entre 0,2 e 0,28 $\%$ (Tabela 1). Os cromatogramas mostram presença de diversos alcalóides secundários, com Rf inferior ao da pilocarpina. Não se pode estabelecer relação entre o teor de pilocarpina e alcalóides totais e os estágios de desenvolvimento da planta. Os resultados obtidos mostram que dificilmente a espécie $P$. pennatifolius constituirá um substituto do P. microphyllus como matéria-prima para a extração de pilocarpina, visto que o teor da mesma em $P$. microphyllus chega a ultrapassar 1,0\%. A presença de diversas manchas de alcalóides secundários recomenda continuação do trabalho de isolamento e determinação de estruturas para a complementação da informação bibliográfica.

\section{Material e métodos}

Material vegetal: As folhas secas de Pilocarpus pennatifolius Lem. foram colhidas na região de San Jorge - Puerto Bossetti (Argentina). Foram utilizadas folhas colhidas dos pés em vários estágios de desenvolvimento.

Determinação de alcalóides totais: Cinco gramas (g) de folhas secas foram extraídas com diclorometano, com agitação por 5 min. Em seguida, adicionaram-se hidróxido de amônio $5 \%$ e agitou-se por $30 \mathrm{~min}$. Filtrou-se a mistura numa solução de ácido sulfúrico a 5\%. Após agitação, a fase orgânica foi transferida para uma solução de ácido sulfúrico 2,5\%. As aquosas ácidas foram reunidas e extraídas com diclorometano. A fase ácida foi neutralizada com hidróxido de amônio ( $\mathrm{pH}$ 9,0). A fase orgânica foi evaporada em placa aquecedora. Ao final da evaporação foram retirados $2,0 \mu \mathrm{l}$ da solução para a análise por CCF contra o padrão de cloridrato de pilocarpina. $\mathrm{O}$ 
resíduo da evaporação foi resfriado, adicionado de ácido sulfúrico 0,05 N, indicador vermelho de metila e titulado com hidróxido de sódio $0,05 \mathrm{~N}$.

A fórmula para calcular a porcentagem de alcalóides totais (AT) é dada como:

$$
\% \mathrm{AT}=\frac{(\text { Vácido }- \text { Vbase }) \times 0,01043 \times 100}{\text { massa da amostra }(\mathrm{g})}
$$

Vácido = volume de ácido sulfúrico

Vbase $=$ volume gasto na titulação $\mathrm{com} \mathrm{NaOH}$

Tabela 1. Relação entre a altura, alcalóides totais o teor de pilocarpina/alcalóides secundários

\begin{tabular}{l|l|l|l}
\hline Amostras & Altura (mts) & \% AT & Rel. pilo/AS \\
\hline 1 & 3,70 & 0,50 & $10: 90$ \\
\hline 2 & 4,75 & 0,43 & $30: 70$ \\
\hline 3 & 3,65 & 0,50 & $30: 70$ \\
\hline 4 & 4,25 & 0,41 & $30: 70$ \\
\hline 5 & 1,50 & 0,42 & $30: 70$ \\
\hline 6 & 7,50 & 0,50 & $30: 70$ \\
\hline 8 & 4,20 & 0,49 & $40: 60$ \\
\hline 9 & 4,33 & 0,53 & $30: 70$ \\
\hline 10 & 1,10 & 0,47 & $30: 70$ \\
\hline 11 & 0,60 & 0,48 & $10: 90$ \\
\hline 12 & 4,00 & 0,51 & $10: 90$ \\
\hline 13 & 0,85 & 0,53 & $30: 70$ \\
\hline 15 & 5,80 & 0,50 & $30: 70$ \\
\hline 16 & 2,10 & 0,53 & $30: 70$ \\
\hline
\end{tabular}

AT = alcalóides totais; pilo= pilocarpina; $\mathrm{AS}=$ alcalóide secundário

\section{Referências}

${ }^{1}$ Benigni, R., Capra, C., Cattorini, P.E. Jaborandi. Pianti Medicinali. Chimica Farmacologia e Terapia, v.2, Parte I, p.781787, 1964

${ }^{2}$ Costa, A.F. Fármacos com alcalóides de núcleo glioxalina. In: Farmacognosia. Lisboa: Fund. Calouste Gulbenkian, 1967. v.2, p.636-643

${ }^{3}$ Guchelaar, H.J., Vermes, A, Meerwald, J.H Radiation-induced xerostomia; pathophysiology, clinical course and supportive treatment. Support Care Cancer, v.5, n.4, p.281-288, July 1997

${ }^{4}$ Lucio, E.M.R.A. et al. Process for the extraction and purification of alkaloids. U.S.Pat. 5.684.155. 4 Nov. 1997

${ }^{5}$ Lucio, E.M.R.A. et al. Process for the extraction and purification of alkaloids. EP 0707589 B1. 7 Oct. 1998

${ }^{6}$ Lucio, E.M.R.A. Estudo químico e farmacológico de alcalóide secundário de Pilocarpus microphyllus Stapf. Tese ( Doutorado em Farmacologia) - Faculdade de Odontologia de Piracicaba, Universidade Estadual de Campinas, 1999. 136p

${ }^{7}$ Pinheiro, C.U.B. Jaborandi (Pilocarpus sp., Rutaceae): A wild species and its rapid transformation into a crop. Economic Botany, v.51, n.1, p.49-58, 1997
${ }^{8}$ Robin, A.L. Ocular hypotensive efficacy and safety of a combined formulation of betaloxol and pilocarpine. Trans Am Ophthalmol Soc, v.94, p.89-101, 1996

9 Taniguchi, T., Kitazawa, Y. A risk-benefit assessment of drugs in the management of glaucoma. Drug saf, v.11, n.1, p.68-74, July 1994

${ }^{10}$ Tsurumi, K. et al. Cathartic activity of spasmogens in mice, rats and guinea-pigs. Nippon Yakurigaku Ku Zasshi, v.75, n.4, p.309-314, May 1979

${ }_{11}$ Zadok, D. et al. Combined timolol and pilocarppine vs pilocarpine alone and timolol alone in the treatment of glaucoma. Am J Ophthalmol, v.117, n.6, p.728-731, June 1994 